\title{
THE SUPPLY OF QUALITY IN CHILD CARE CENTERS
}

\author{
David M. Blau and H. Naci Mocan*
}

Abstract - We use data from a sample of child care centers to estimate the relationships between cost and child care quality, and between revenue and quality. We use a measure of child care quality, designed by developmental psychologists, that is positively associated with child development. Taking the estimated cost-quality and revenue-quality relationships as given, we estimate the objective functions of firms and compute the quality supply function. The results indicate that the supply of quality is moderately elastic with respect to price and the wages of child care center workers. Implications of the results for child care policy are discussed.

\section{Introduction}

$\mathrm{D}$ EVELOPMENTAL psychologists assert that the cognitive, social, and emotional development of children is enhanced by exposure to high-quality child care and is harmed by exposure to low-quality care (Hayes, Palmer, \& Zaslow, 1990). The quality of child care services in the United States is thought to be mediocre on average, particularly in comparison to the quality of care provided in other developed countries (Whitebook, Howes, \& Phillips, 1990; Mocan, 1997; Bergmann, 1996). There is considerable interest among policymakers in finding ways to increase the quality of child care in the United States. For example, the Federal Child Care Development Block Grant stipulated that a portion of funds appropriated under the grant be set aside for "quality-improving" activities. However, using government policy to accomplish this goal will be difficult without understanding the behavior of firms supplying day care services, the "technology" of day care, and the resulting relationships among quality, cost, and the price of care. ${ }^{1}$ Until recently, little was known about these important issues in the child care market. Mocan $(1995,1997)$ provided the fist analysis of the cost-quality relationship for day care centers with results that are useful for public policy, including an estimate of the cost of increasing quality. We build on Mocan's analysis by estimating the supply function for quality. Our results provide a basis for analyzing the impact of alternative forms of government subsidies that are intended to improve child care quality.

An important issue in conducting such an analysis is the appropriate definition of child care quality. Several previous

Received for publication September 26, 2000. Revision accepted for publication November 13, 2001.

* University of North Carolina-Chapel Hill, and University of Colorado-Denver and National Bureau of Economic Research, respectively.

This is a substantially revised version of NBER working paper no. 7225 . We are grateful to Erdal Tekin for excellent research assistance and to Paul Rhode, Ed Olsen, Derek Neal, Ken Wolpin, participants at numerous seminars, and two referees for helpful comments on previous drafts. Financial support from NICHD (Blau) and NBER (Mocan) is gratefully acknowledged. We are responsible for all opinions and errors.

${ }^{1}$ Day care centers accounted for $30 \%$ of all primary child care arrangements for preschool children of employed mothers in 1993 (Casper, 1997). In-home babysitters and family day care providers constituted $21 \%$ of arrangements, but there is much less information available about such providers. Relatives, including the father and the mother (while working), accounted for the remaining child care for preschool children of employed mothers. analyses of the cost-quality relationship in day care centers included variables such as the child-staff ratio, group size, and the average education of the staff as proxies for quality in the cost function (Preston, 1993; Mukerjee \& Witte, 1993; Powell \& Cosgrove, 1992). However, these variables are more appropriately thought of as inputs to the production of quality, and as such do not belong in the cost function. ${ }^{2}$ In other contexts, the quality of child care purchased by a family has been treated as exogenous (Ribar, 1995), as equivalent to the family's expenditure on child care (Michalopoulos, Robins, \& Garfinkel, 1992), as an unobserved variable proxied by the mode of care, such as day care center, family day care home, and so on (Leibowitz, Waite, \& Witsberger, 1988), or as an unobserved choice variable (Blau \& Robins, 1988; Connelly, 1992). In this paper, we take a different approach. Developmental psychologists define the quality of child care by the developmental appropriateness of the interactions between the provider and the child, and the environment, curriculum, materials, and activities to which children are exposed. Psychologists have designed instruments to measure the quality of child care defined in this way. For example, teaching staff can be rated by observers on aspects of care such as how sensitive they are to children, whether they encourage children to engage in activities, and whether they use positive guidance techniques. As measured by these instruments, child care quality has a positive effect on child development. This is not surprising because child care quality is defined by provider behavior and environments that have been determined through research and practice to foster child development (Love, Schochet, \& Meckstroth, 1996).

We believe that the concept of child care quality developed by psychologists is the appropriate one for our purposes. Arguments for government intervention in the child care market are often based on the externalities generated by exposing children to high-quality care (Council of Economic Advisors, 1997; Robins, 1991; Hayes et al., 1990). Other common arguments for intervention in the child care market are that parents are unaware of the benefits of high-quality care or lack the ability to discern the quality of care (Walker, 1991). It makes sense, therefore, to use a measure of quality that is known to be correlated with child development when analyzing the supply of quality in child care.

We use a measure of child care quality that is derived from an instrument designed by developmental psychologists. This

\footnotetext{
${ }^{2}$ Another problem with treating these variables as proxies for quality is that they do not appear to be closely related to either the quality of care or child development (Blau, 1997, 1999, 2000). This is similar to the common finding in the literature on schools that observable resources have little measurable impact on student outcomes (Hanushek, 1994). See Gertler and Waldman (1992) for an analysis of the cost function for nursing homes that treats quality as an unobserved choice variable of the firm.
} 
instrument was used to rate the quality of care in a stratified random sample of four hundred day care centers in four states. Detailed data on costs, inputs, prices, and other key variables were collected for the same centers, and we use these data to estimate the cost function and the market price-quality locus facing day care centers. These two functions are the constraints faced by day care centers in their efforts to achieve their objectives. Taking these estimated constraints as given, we then estimate the objective functions of the firms in our sample. We assume that firms care about profit and quality, and we estimate the relative weights attached to these two variables, using variation across firms in the constraint functions they face to identify these weights. This variation arises from variation in geographical location of the firms, both across and within states. We allow for-profit and nonprofit firms to have different relative weights on profit and quality, and we specify and estimate additional constraints on the profit that can be earned by nonprofit centers as a result of their nonprofit legal status. We use the estimated constraint and objective functions to simulate the supply of quality and the response of firms to subsidies intended to increase the quality of child care. The main empirical finding is that the supply of quality is moderately responsive to price and wages.

In the following sections of the paper, we specify a model of day care center behavior, describe our econometric methods, discuss the data, and present the results. The final section concludes with a discussion of the implications of the findings.

\section{A Model of Day Care Center Behavior}

The basic premise of the analysis is that the market for center-based child care is in competitive equilibrium. Competition results in an equilibrium price-quality locus that individual day care providers and consumers take as given. Quality here is defined as the developmental appropriateness of the care provided and is assumed to be observable by consumers. By choosing the quality of care to offer, firms determine the price they can charge, and, by choosing the center from which to purchase care, consumers determine the price of care they will pay and the quality of care they receive. Consumers might care about many aspects of child care other than quality, but we focus on quality because of its importance for child development. Evidence (presented later) shows that quality and price are positively related, but that most other easily observed attributes of child care are not associated with price. Child care markets are location specific, and variation across locations in the position and shape of the equilibrium price-quality locus provides the information needed to identify the quality supply behavior of firms. This variation arises from differences in market conditions across locations. In the following subsections, we fill in the details of this framework.

\section{A. Technology and Cost}

Both for-profit and nonprofit firms are assumed to be cost minimizers. The firm chooses the weekly number of hours of each type of staff (differentiated by skill) and the number of groups to which children will be assigned to minimize cost subject to the quality production function and given values of quality and wages by skill level. We treat the quantity of output and the characteristics of the families and children served by a center as determined by choices made by consumers, given the price and quality set by the firm. ${ }^{3}$ We do not explicitly model nonpersonnel inputs because we have little information on input prices other than staff compensation. The cost function for center $j$ has the form

$$
C_{j}=C\left(W_{j 1}, \ldots, W_{j T}, H_{j}, Q_{j}, Z_{j}, M_{j}, G_{j}, v_{j}\right),
$$

where $C$ is cost, $W_{j i}$ is the wage rate for the $i^{\text {th }}$ type of staff, there are $T$ different types of staff,

$H$ is the quantity of care (child hours),

$Q$ is quality,

$Z$ is a set of fixed center characteristics,

$M$ is a set of parent and child characteristics,

$G$ is the number of groups (classrooms), and

$v$ is a disturbance.

$G$ belongs in the cost function because it determines how many staff hours are required to provide care for the quantity of child care services $(H)$ demanded of the firm. ${ }^{4}$

\section{B. Price Determination}

Following the literature on demand for differentiated products (Rosen, 1974) and its application to child care (Blau \& Hagy, 1998; Hagy, 1998; Walker, 1992), we assume that there exists an equilibrium price-quality locus in firm j's market:

$$
P_{j}=P\left(Q_{j}, X_{m(j)}\right),
$$

where $X_{m(j)}$ represents factors that shift the locus, such as the size and characteristics of the market, $m(j)$, in which firm $j$ is

\footnotetext{
${ }^{3}$ In the empirical analysis, we allow for the possibility that wages and the quantity and quality of care are endogenous as a result of unobserved heterogeneity. Another set of constraints that a firm might face in minimizing cost is state regulations governing the maximum allowable group size, the minimum allowable staff-child ratio, and the qualifications of the staff. It is straightforward to incorporate such regulations in the model, but we do not do so here because regulations do not appear to be binding constraints on most of the firms in our sample. We discuss this later.

${ }^{4}$ The cost minimization problem underlying equation (1) is to choose $N_{j 1}-N_{j T}$ and $G_{j}$ to

$$
\operatorname{Min} \mathscr{L}=\sum_{i=1}^{T} N_{j i} W_{j i} G_{j}+\lambda_{j}\left[Q_{j}-Q\left(N_{j 1}, \ldots, N_{j T}, H_{j}, g_{j}, Z_{j}, M_{j}\right)\right] \text {, }
$$
}

where $N_{j i}$ is the number of hours of labor of staff type $i$ used per room, $g \equiv H / G$ is group size measured in child hours, and $Q()$ is the quality production function. 
located. Firms and consumers are assumed to take the pricequality locus as given: it is determined by market supply and demand, not by the actions of any individual firm or consumer.

\section{Quality Supply}

We follow Lakdawalla and Philipson (1998) and assume that firms care about both profit and quality, with an objective function of the form $U\left(Q_{j}, \pi\left(Q_{j}\right)\right)$, where $\pi$ represents the firm's profit. ${ }^{5}$ If $U_{Q} \neq 0$, the firm is said to have "profitdeviating" preferences. A center with for-profit legal status could have profit-deviating preferences or could be a profitmaximizer $\left(U_{Q}=0\right)$. The same is true for a center with nonprofit status: nonprofit firms may care about quality because many such firms were started for the purpose of providing high-quality child care services in order to correct a perceived market failure. For-profit firms may behave as if they care about quality if they compete for customers with nonprofit firms. ${ }^{6}$ A for-profit center chooses $Q$ to maximize $U(Q, \pi(Q))$ subject only to the $\pi(Q)$ constraint, whereas a nonprofit center chooses $Q$ to maximize $U(Q, \pi(Q))$ subject to $\pi=\pi(Q)$ and $\pi_{1} \leq \pi \leq \pi_{\mathrm{u}}$, where $\pi_{1}$ is the minimum level of profit needed to survive in the long run (which could be negative), and $\pi_{\mathrm{u}}$ is the legal upper limit on the profit that can be earned by a nonprofit center. As noted, cost minimization is assumed in both cases. The first-order condition (FOC) determining the optimal choice of quality in a for-profit center is

$$
U_{Q}+U_{\pi}(M R-M C)=0,
$$

where $M R$ is marginal revenue and $M C$ is marginal cost. If the constraint $\pi_{1} \leq \pi \leq \pi_{\mathrm{u}}$ is not binding, then equation (3) also characterizes the behavior of a nonprofit center. If $\pi \leq$ $\pi_{\mathrm{u}}$ is binding, then the FOC is $\pi\left(Q_{j}\right)=R\left(Q_{j}\right)-C\left(Q_{j}\right)=$ $\pi_{\mathrm{u}}$, where $R$ is revenue and $C$ is cost. If $\pi_{1} \leq \pi$ is binding, then the FOC is $\pi\left(Q_{j}\right)=R\left(Q_{j}\right)-C\left(Q_{j}\right)=\pi_{1}$.

\section{Empirical Implementation}

A considerable amount of specification searching led us to choose a relatively simple form of the cost function. We specify the logarithm of cost as a linear function of quality, with no interactions between quality and other variables, and no higher-order terms in quality. The semi-log specification gave the best fit and the most sensible results. There

\footnotetext{
${ }^{5}$ Lakdawalla and Philipson (1998) use output rather than quality as the argument of the utility function. Quality seems the more natural variable to use here because it is plausible that centers may care about quality and it is unlikely that size or market share is important in day care. See Hansmann (1996), Weisbrod (1998), and Rose-Ackerman (1996) for discussion of the behavior of nonprofit firms.

${ }^{6}$ Tabulations from the Profile of Child Care Settings (PCS) data (Kisker et al., 1991) indicate that $25.5 \%$ of nonprofit day care centers gave "promoting child development" as their primary goal, $15.1 \%$ gave "preparing children for school," $6.2 \%$ gave "providing compensatory education for disadvantaged children," and $1.4 \%$ gave teaching appreciation for culture. These can all be considered quality-related goals. The corresponding figures for for-profit centers are $13.1 \%, 12.0 \%, 0.2 \%$, and $0.5 \%$, respectively. We computed these figures from the PCS data.
}

was little evidence of direct interactions between quality and other determinants of cost, although the semi-log function implicitly interacts quality with all other variables in determining cost. The specification is

$$
\begin{aligned}
\operatorname{Ln} C_{j}= & \beta_{0}+\beta_{1} Q_{j}+\beta_{2} H_{j}+\beta_{3} g_{j}+\beta_{4} H_{j}^{2}+\beta_{5} g_{j}^{2} \\
& +\beta_{6} H_{j} g_{j}+\beta_{7} Z_{j}+\beta_{8} M_{j} \\
& +\sum_{i=1}^{T} \beta_{8+i} W_{j i}+\nu_{j} .
\end{aligned}
$$

The higher-order terms in $H$ and $g$ are included because they improved the fit of the model. ${ }^{7}$ We later discuss the sensitivity of the main results to alternative specifications of the cost function. It is possible to test the estimated cost function for consistency with the restrictions implied by cost minimization, but we do not do so. The reason is that we have little information on the nonlabor determinants of cost. Labor accounts for approximately $70 \%$ of cost on average in the data we use, but without information on the prices of nonlabor inputs we cannot impose and test adding-up constraints. For example, rent per square foot is not available for centers that use partially or completely donated space, and our attempts to obtain this information from local real estate agencies generated incomplete data that did not contain much within-state variation. Similarly, there is no significant variation in the prices of materials (such as paper towels, snacks and crayons), because of competition at the wholesale level within states.

Quality, child hours, group size, and wages may be endogenous in the cost function if there is unobserved heterogeneity across firms. ${ }^{8}$ For example, firms that have high costs as a result of high wages may also have high costs for other reasons that we cannot measure, as a result of being located in a high-cost area. Firms that economize on cost by using large group size may economize on cost in other ways that cannot be observed. Staff who are dedicated to providing high-quality care might help firms reduce cost in ways that cannot be measured, such as providing greater effort per hour. Our identification strategy assumes that location within a state (state dummies are included in the cost function in $Z_{j}$ ), as defined by a center's ZIP code or town, is uncorrelated with technology but is correlated with these potentially endogenous regressors. In other words, we assume that the location of a center is exogenous and that location affects cost only via its effects on $g, Q, H$, and $W_{1}-W_{T}$. We operationalize this by using ZIP code or town dummies as instruments in first-stage equations for $g, Q, H$, and the $W$ 's.

\footnotetext{
7 The specification in equation (1) includes the number of groups $(G)$, but, in equation (4), we include group size, $g=H / G$, which is just a transformation of $G$, conditional on $H$.

${ }^{8}$ It is possible that some of the child and family characteristics in $M_{j}$ and some of the center characteristics in $Z_{j}$ are endogenous as well. We ignore this possibility because of the very large number of parameters that would have to be estimated if models for $M_{j}$ and $Z_{j}$ were added.
} 
Another potential problem is that not all centers are at an interior solution with respect to the choice of staff: some centers do not use any staff of certain types. This is true regardless of how staff are classified. One way to deal with this is to include all centers in the analysis by assigning imputed wages to centers that do not use specific types of staff. ${ }^{9}$ But theory implies that these centers would respond differently to changes in wages than would centers at the full interior solution. Instead, we estimate the cost function using the subsample of centers at the full interior solution. A disadvantage of this approach is a smaller sample size: 266 centers use all types of labor input based on the classification described below, whereas the full sample contains 370 centers with non-missing data. We report below on the robustness of the results to selection of the sample on the basis of this possibly endogenous variable.

The price equation is specified as a double-log model:

$$
\operatorname{Ln} P_{j}=\theta_{m(j)}+\omega \ln Q_{j}+\eta I_{j}+u_{j}
$$

where $I_{j}$ is the proportion of infant-toddlers among center $j$ 's children,

$\theta_{m(j)}$ is an intercept that is specific to the location $m(j)$ of center $j$,

$\omega$ and $\eta$ are parameters, and

$u_{j}$ is a disturbance.

This functional form consistently fit the data better than did the alternatives. In the estimation, we specify the location-specific intercepts by dummies at either the ZIP code or town level. Thus, the intercept of the price function is allowed to vary freely across towns or ZIP codes, which are assumed to constitute the relevant markets. The quality parameter, $\omega$, is restricted to be the same across ZIP codes or towns within a state, but is allowed to vary across states. The dependent variable is the logarithm of the weighted average fee of the center by age group of children, weighted by the proportion of children in each age group. We include the proportion of infant-toddlers as an explanatory variable because fees tend to be higher for younger children. Experimentation with the equation suggested that conditional on ZIP code fixed-effects unobserved heterogeneity is not a problem, so we estimate it by ordinary least squares (OLS). ${ }^{10}$

We adopt a Cobb-Douglas specification of the objective function, $U(Q, \pi(Q))=Q_{j}^{\alpha} \pi_{j}^{1-\alpha}$, where $\alpha$ is allowed to differ between for-profit and nonprofit firms. Profit maximization implies $\alpha=0$. The FOC for a for-profit center implies that

\footnotetext{
${ }^{9}$ Mocan (1997) followed this approach, and we later examine the sensitivity of our results to this alternative approach.

${ }^{10} \mathrm{We}$ augmented the specification in equation (5) with fifteen characteristics of centers and four characteristics of the parents of the children served by the centers. Conditional on the ZIP code fixed effects, we could not reject the hypothesis that these characteristics could be excluded from the regression. Most of the coefficient estimates on the characteristics were insignificantly different from zero individually as well.
}

$$
(M C(Q)-M R(Q))=\alpha \pi /(1-\alpha) Q+\epsilon
$$

where

$$
\begin{aligned}
& \text { Revenue }=R=H_{j} P_{j}=\exp \left\{\theta_{m(j)}+\omega \ln Q_{j}+\eta I_{j}\right\} H_{j}, \\
& M R=\partial R / \partial Q=\omega R_{j} / Q_{j}, \\
& M C=[\partial \ln C / \partial Q] C(Q) \text {, and } \\
& \epsilon \text { is measurement error in } M C-M R .
\end{aligned}
$$

Equation (6) is a nonlinear implicit equation for the optimal $Q$. Given estimates of $\alpha$ and the parameters of the cost and price equations, along with data on $I_{j}, H_{j}$, and the other arguments of the cost function, it is straightforward to solve equation (6) numerically for the implied optimal value of $Q$.

A nonprofit center for which the constraint $\pi_{1} \leq \pi \leq \pi_{\mathrm{u}}$ is not binding has a FOC of the same form as equation (6). A nonprofit center that would have chosen $\pi>\pi_{\mathrm{u}}$ in the absence of a constraint will be forced to set $Q$ so that $\pi(Q)=R(Q)-C(Q)=\pi_{\mathrm{u}}$. We assume that $\pi_{\mathrm{u}}$ is known to the firm but unobserved by us. It can therefore be treated as a disturbance. Similarly, a firm that hits the $\pi_{1} \leq \pi$ constraint will be forced to set $\pi=\pi_{1}$, and we treat $\pi_{1}$ as observed by the firm but unknown to us. This results in a switching regression model with unknown regime. We do not know whether any particular nonprofit center is in the unconstrained regime $\left(\pi_{1}<\pi<\pi_{\mathrm{u}}\right)$ or one of the constrained regimes $\left(\pi=\pi_{\mathrm{u}}\right.$ or $\left.\pi=\pi_{1}\right)$. The model governing the choice of $Q$ in the unconstrained regime is equation (6), and in the constrained regimes is $R(Q)-C(Q)=\pi_{\mathrm{u}}$ or $R(Q)-C(Q)=\pi_{\mathrm{l}}$, which are implicit equations for $Q$. We assume that $\epsilon \sim N\left(0, \sigma^{2}\right)$ (with $\sigma$ allowed to differ by profit status), $\pi_{\mathrm{u}} \sim N\left(\mu_{\mathrm{u}}, \sigma_{\mathrm{u}}^{2}\right)$, and $\pi_{1} \sim N\left(\mu_{\mathrm{l}}, \sigma_{1}^{2}\right)$. The probability that a nonprofit center is constrained by $\pi_{1}$ is $\lambda_{1}=\operatorname{Pr}\left(\pi_{1}>\right.$ $\left.\pi^{*}\right)$, where $\pi^{*}$ is the unconstrained level of profit, which is the solution to equation (6):

$$
\begin{aligned}
\lambda_{1}= & \operatorname{Pr}\left(\pi_{1}>\pi^{*}\right)=\operatorname{Pr}\left(\pi_{1}>\left(M C\left(Q^{*}\right)-\operatorname{MR}\left(Q^{*}\right)\right)\right. \\
& \left.\times(1-\alpha) Q^{* / \alpha}\right)
\end{aligned}
$$

where $Q^{*}$ is the unconstrained choice for $Q$, which is found by solving equation (6) numerically. The probability that a center is constrained by $\pi_{\mathrm{u}}$ is

$$
\begin{aligned}
\lambda_{\mathrm{u}}= & \operatorname{Pr}\left(\pi_{\mathrm{u}}<\pi^{*}\right)=\operatorname{Pr}\left(\left(M C\left(Q^{*}\right)-M R\left(Q^{*}\right)\right)\right. \\
& \left.\times(1-\alpha) Q^{*} / \alpha>\pi_{\mathrm{u}}\right) .
\end{aligned}
$$

Taking the parameters of the cost and fee equations as given, the likelihood function contribution for a nonprofit child care center is

$$
\begin{aligned}
L=[\phi & \left.\left(\left(R[Q]-C[Q]-\mu_{1}\right) / \sigma_{1}\right) \sigma_{1}\right]^{\lambda_{1}}[\phi((R[Q] \\
& \left.\left.\left.\left.-C[Q]-\mu_{\mathrm{u}}\right) / \sigma_{\mathrm{u}}\right) / \sigma_{\mathrm{u}}\right]^{\lambda_{\mathrm{u}}}[\phi(\epsilon / \sigma) / \sigma)\right]^{1-\lambda_{1}-\lambda_{\mathrm{u}}},
\end{aligned}
$$


where $\phi$ is the probability density function of a standard normal variate. The parameters to be estimated are $\alpha, \sigma, \mu_{l}$, $\mu_{\mathrm{u}}, \sigma_{\mathrm{l}}$, and $\sigma_{\mathrm{u}}$. We restrict $\alpha$ to the unit interval. Testing the hypothesis of profit maximization involves a restriction on $\alpha$ and is straightforward. The likelihood contribution for a for-profit center is $L=\phi(\epsilon / \sigma) / \sigma$.

With estimates of $\alpha, \mu_{\mathrm{u}}, \mu_{1}$ and the parameters of the cost and fee equations, we solve numerically for the quality supply function, $Q=Q^{*}\left(\omega, W_{1}, \ldots, W_{T}, H, g, R, M\right)$, which shows how quality supplied varies with the determinants of price and cost. The quality supply function for nonprofits accounts for the different regimes by weighting by the estimated values of the $\lambda$ 's. Because price is determined by the firm's choice of quality, we cannot compute a conventional supply function. Instead, we simulate supply behavior by varying the intercept of the price function $(\theta)$, and solving for each firm's profit-maximizing choice of quality for alternative values of $\theta$. We then average over firms. This measures how a firm would respond to an exogenous change in the intercept of the price-quality relationship in its market.

\section{Data}

We use data collected from day care centers in California, Colorado, Connecticut, and North Carolina as part of the Cost, Quality, and Outcomes (CQO) Study. A random sample of fifty for-profit and fifty nonprofit day care centers providing full-time, year-round care was selected from specified regions within each state. ${ }^{11}$ Interviewers visited each center in the spring of 1993 and gathered detailed information on costs, revenues, donations, quality, and the human capital characteristics and wages of every worker. In addition to information collected from interviewing the center director, two rooms at each center were randomly chosen to be observed: one preschool and one infant-toddler room if the center served both age groups. ${ }^{12}$ Trained observers visited each center for one day to observe the rooms. The Early Childhood Environment Rating Scale (ECERS) and the Infant-Toddler Environment Rating Scale (ITERS) were used to measure the quality of care provided in the selected rooms. These instruments contain approximately thirty items characterizing personal care routines, furnishings, language-reasoning experience, fine and gross motor activities, creative activities, and social development. Each item is scored on a seven-point scale with a score of 1 representing inadequate and a score of 7 representing excellent. These are widely used instruments, and have good psychomet-

\footnotetext{
${ }^{11}$ The regions were Los Angeles County; the "Front Range" area of Colorado Springs, Denver, Boulder, Fort Collins, and Greeley; the Hartford-New Haven corridor; and the "Triad" area of Winston-Salem, Greensboro, and Burlington.

${ }^{12}$ Infant-toddler rooms were defined as those in which the majority of children were less than 2.5 years old. Preschool classrooms were defined as those in which the majority of children were at least 2.5 years old, but not yet in kindergarten. No school-age or kindergarten classrooms were observed.
}

ric properties. ${ }^{13}$ In essence, they formalize the notions of quality that a well-educated parent might look for when visiting a center, such as the nature of the interactions between staff and children; the developmental appropriateness of the materials, toys, playground equipment, and activities; and the hygiene and food preparation practices of the center. (The appendix provides a list of items and examples of instructions to the observers on how to score items.) We use the average score across the items as our measure of quality. The descriptive statistics shown in table 1 indicate that average quality is higher in nonprofit centers; this is due largely to a pronounced difference between the quality of for-profit and nonprofit centers in North Carolina. ${ }^{14}$

Cost is the sum of annual wage and salary expenditure, nonwage benefits, staff education costs, subcontracting costs, food costs, other operating expenses, the estimated value of in-kind donations (food, volunteer services, and supplies), overhead, insurance, and occupancy costs (rent or mortgage, utilities, repair and maintenance). This is a comprehensive measure of total cost that treats all inputs as variable. Hence, the cost function we estimate is a long-run cost function, in contrast to the short-run cost function estimated by Mocan (1997) using the same data. We expect cost to be more inelastic with respect to quality in the long run than in the short run. For centers that use donated space, the annual rental value of the space is calculated and treated as occupancy cost. For centers that receive financial help with rent, the discount they receive on rent is added to occupancy costs. Because our aim is to estimate a long-run cost function in which all inputs are treated as variable, we include all costs. ${ }^{15}$ The rationale for including the value of donated inputs is that a cost-minimizing firm will account for all costs when making decisions, including costs that are implicit, and full cost is clearly the relevant concept for policy purposes. Excluding the cost of donated inputs would make it appear that nonprofits are more efficient than for-profits, which is unlikely a priori. Annual cost is divided by 52 to obtain a measure of weekly total cost that is used in the estimation. The center director provided information on the total number of children enrolled in the center by age, average hours per child by age, and the number of rooms by age. As shown in table 1, average weekly cost per child is

\footnotetext{
${ }^{13}$ See Harms and Clifford (1980) and Harms, Cryer, and Clifford (1990) for details. Several other instruments were used as well, but we focus on the ECERS and ITERS as our measure of quality. Inter-rater reliability at each site and between sites was very high for all instruments used (Helburn, 1995).

${ }^{14}$ Additional descriptive information by state and profit status can be found in Mocan (1997) and Helburn (1995). Our measure of quality is a simple average of the quality of the two observed rooms in a center. We also experimented with a weighted average measure in which the quality score of a room was weighted by the proportion of rooms of its age group. The results were virtually identical to those we report here.

${ }^{15}$ Nonprofit centers that rely heavily on donated space may face a constraint on expansion if they already use the space to capacity. We added a measure of square feet of space to the cost function for nonprofits and found that its coefficient estimate was highly significant, but the basic implications of the analysis were unchanged.
} 
TABle 1.-Descriptive Statistics

\begin{tabular}{|c|c|c|c|}
\hline & All & For-profit & Nonprofit \\
\hline Total weekly cost & $5,920(3,700)$ & $6,010(3,079)$ & $5,824(4,264)$ \\
\hline Enrollment & $75(47)$ & $81(49)$ & $68(44)$ \\
\hline Average weekly hours of care provided & $2,887(1,884)$ & $3,022(1,767)$ & $2,745(1,994)$ \\
\hline Average weekly cost per child & $89(41)$ & $88(42)$ & $91(40)$ \\
\hline Average quality of care & $4.1(0.9)$ & $3.9(0.9)$ & $4.2(0.9)$ \\
\hline California & $4.5(0.9)$ & $4.3(0.8)$ & $4.6(0.9)$ \\
\hline Colorado & $4.1(0.8)$ & $4.0(0.7)$ & $4.3(0.8)$ \\
\hline Connecticut & $4.2(1.0)$ & $4.3(1.0)$ & $4.0(1.0)$ \\
\hline North Carolina & $3.5(0.9)$ & $3.0(0.7)$ & $4.0(0.9)$ \\
\hline Total weekly cost/quality & $1,494(900)$ & $1,560(770)$ & $1,425(1,017)$ \\
\hline Average cost per child/quality & $22.6(10.8)$ & $22.5(9.9)$ & $22.6(11.6)$ \\
\hline Average group size & $14.6(6.5)$ & $14.4(6.9)$ & $14.8(6.1)$ \\
\hline \multicolumn{4}{|l|}{ Average weekly teacher hours per room } \\
\hline Educ $\leq 12$ & $31.4(21.6)$ & $28.6(21.0)$ & $34.3(21.8)$ \\
\hline Educ $=13-15$ & $30.9(21.8)$ & $29.4(21.0)$ & $32.3(22.6)$ \\
\hline Educ $\geq 16$ & $29.3(22.9)$ & $26.7(20.5)$ & $32.0(25.0)$ \\
\hline \multicolumn{4}{|l|}{ Average teaching staff compensation/hour } \\
\hline Educ $\leq 12$ & $6.86(2.02)$ & $6.52(1.68)$ & $7.22(2.29)$ \\
\hline Educ $=13-15$ & $7.75(2.80)$ & $7.43(3.11)$ & $8.10(2.38)$ \\
\hline Educ $\geq 16$ & $9.71(4.24)$ & $8.90(4.10)$ & $10.55(4.23)$ \\
\hline For-profit center & $0.51(0.50)$ & $1.00(0)$ & $0(0)$ \\
\hline Percentage of children white & $71(29)$ & $79(22)$ & $63(33)$ \\
\hline Meets higher standards (pubregul) & $0.06(0.25)$ & 0 & $0.13(0.34)$ \\
\hline$>50 \%$ of revenue from subsidies (pubsub) & $0.09(0.28)$ & $0.03(0.17)$ & $0.15(0.35)$ \\
\hline Church-affiliated & $0.22(0.42)$ & 0 & $0.45(0.50)$ \\
\hline Years in operation & $13.1(12.5)$ & $9.8(8.3)$ & $16.7(15.1)$ \\
\hline Proportion of infant-toddler rooms & $0.33(0.26)$ & $0.39(0.24)$ & $0.27(0.28)$ \\
\hline Proportion of preschooler rooms & $0.48(0.25)$ & $0.42(0.22)$ & $0.55(0.27)$ \\
\hline Annual family income/1000 & $53(24)$ & $60(24)$ & $45(23)$ \\
\hline Proportion of children with married parents & $0.71(0.24)$ & $0.77(0.19)$ & $0.65(0.28)$ \\
\hline Proportion of children with at least one college graduate parent & $0.45(0.26)$ & $0.51(0.25)$ & $0.39(0.26)$ \\
\hline Located in California & $0.22(0.42)$ & $0.21(0.41)$ & $0.24(0.43)$ \\
\hline Located in Colorado & $0.28(0.45)$ & $0.29(0.45)$ & $0.28(0.45)$ \\
\hline Located in Connecticut & $0.27(0.45)$ & $0.30(0.46)$ & $0.24(0.43)$ \\
\hline Located in North Carolina & $0.23(0.42)$ & $0.21(0.41)$ & $0.25(0.43)$ \\
\hline Average hourly fee & $2.10(0.83)$ & $2.26(0.75)$ & $1.94(0.87)$ \\
\hline Number of centers & 266 & 136 & 130 \\
\hline
\end{tabular}

Entries are means and, in parentheses, standard deviations.

slightly higher in nonprofit centers. Average cost per unit of quality is lower in nonprofit centers, but average cost per child per unit of quality is virtually identical in for-profit and nonprofit centers.

The center director provided a roster of all workers in the center, including data on the hourly wage or annual salary, hours of work per week, years of experience, tenure at the center, training, age, race, gender, the age group of children served, and the worker's job title. After considerable experimentation, we classified staff into three categories by years of formal education: high school graduate or less, some college, and college graduate or more. The survey contains detailed information on the specific type and source of child-development-related training of each staff member. In preliminary analyses, we found that this additional training information was for the most part redundant once staff were categorized by years of schooling. Table 1 shows descriptive statistics on staff hours and hourly compensation by staff type. Compensation consists of average hourly earnings plus estimated average fringe benefits per hour. ${ }^{16} \mathrm{Com}-$

\footnotetext{
16 Wages are averaged over all staff with a given level of education. The center's total expenditure on fringe benefits is divided by total staff hours to measure the average hourly value of fringe benefits.
}

pensation rises with education, but not by as much as in other jobs held by women (Blau, 2001; Mocan \& Tekin, 2000). Nonprofit centers pay $9 \%-18 \%$ higher wages than do for-profits.

Group size is derived from a roster of all the rooms in the center that lists the number of children enrolled in each room and their age group. Also available are alternative measures based on the number of children present in each room on the day of the interview and on measures of group size recorded during the morning observation period for the two rooms observed. The results of the analysis using these alternative measures were similar to the results based on enrollment.

Table 1 shows descriptive statistics on the room-specific family characteristics of the enrolled children $\left(M_{j}\right)$. These were collected in a survey instrument distributed to the parents of children in the observed rooms. We use three of the variables available in this survey that were consistently important across specifications: family income, marital status, and the percentage of families in which at least one parent has graduated from college. Table 1 also describes the center characteristics included in the analysis $\left(Z_{j}\right)$. These variables are included to measure "fixed factors" that may affect cost. They include state dummies; an 
indicator of for-profit status; indicators of whether the center receives public money tied to meeting higher than normal standards (pubregul); ${ }^{17}$ whether the center receives more than half its revenue from public grants, public fees, and USDA reimbursement (pubsub); whether the center has a religious affiliation; the center's age, the percentage of children who are white; and the proportion of infant-toddler and preschooler-age rooms in the center. The age and racial composition of children served will affect cost if they affect the marginal product of staff input in the production of quality.

As noted in section II, we ignore state regulations on group size, staff-child ratio, and staff qualifications. If regulations affected the behavior of centers, then we would expect to find many centers with a group size and staff-child ratio at or close to the regulation. Elsewhere (Blau \& Mocan, 2000), we present a detailed analysis of compliance with regulations and the effects of regulations on day care center behavior. We show that most centers have more staff per child and smaller group size than is required by regulations. Up to $20 \%$ of centers are out of compliance with regulations, often by a substantial margin (for example, a group size of twenty when the regulated maximum is fifteen). This suggests that regulations are not strictly enforced and thus need not be incorporated in the analysis.

\section{Results}

\section{A. Cost Function Estimates}

The baseline cost function results, presented in table 2, were estimated by OLS. We later report additional results based on instrumental variable (IV) and selectivitycorrected estimation. We treat the OLS estimates as a baseline because evidence presented here indicates that the hypothesis that quality, quantity, wages, and group size are exogenous cannot be rejected. The main finding in table 2 is that quality is positively related to cost, with a coefficient estimate of 0.056 that is significantly different from zero. The estimate implies that a unit increase in quality (equal to about one standard deviation) raises cost by $5.6 \%$ on average. Cost increases with output at a decreasing rate, with the marginal effect remaining positive throughout the observed range of output in the data. Cost is positively related to wages of all three teacher types, with the wage rate of the least-educated workers showing the biggest effect. Costs are on average similar in Colorado and California (the omitted category), higher in Connecticut, and lower in North Carolina. Costs are higher for older centers, centers that voluntarily meet higher than required standards (pubregul), centers that serve a higher proportion of infants and toddlers,

\footnotetext{
17 This group includes Head Start programs, centers in which $20 \%$ or more of the enrollment are special-needs children, special preschool programs sponsored by the state or federal Department of Education, and other special programs in Connecticut and California.
}

Table 2.-Log Weekly Total Cost Function Parameter Estimates

\begin{tabular}{lc}
\hline \hline Quality $(Q)$ & $0.056(0.023)^{*}$ \\
Annual hours of care/1000 $(H)$ & $0.0085(0.0007)^{* *}$ \\
$H^{2} / 10000$ & $-0.144(0.020)^{* *}$ \\
Group size $(g)$ & $0.0009(0.0094)$ \\
$g^{2} / 100$ & $-0.028(0.044)$ \\
$H^{*} g$ & $-0.28(0.22)$ \\
Teacher wage, educ. $\leq 12$ & $0.027(0.014)$ \\
Teacher wage, educ. $=13-15$ & $0.019(0.009)^{*}$ \\
Teacher wage, educ. $\geq 16$ & $0.010(0.005)^{*}$ \\
For profit & $-0.053(0.055)$ \\
CO & $0.00(0.07)$ \\
CT & $0.11(0.06)$ \\
NC & $-0.19(0.07)^{* *}$ \\
Percentage of children white & $0.0005(0.0008)$ \\
More than 50\% of revenue from subsidies $(p u b s u b)$ & $0.018(0.084)$ \\
Years in operation & $0.0026(0.0017)$ \\
Church affiliated & $-0.17(0.06)^{* *}$ \\
Meets higher standards (pubregul $)$ & $0.29(0.10)^{* *}$ \\
Parents college & $0.22(0.10)^{*}$ \\
Parent income & $-0.0006(0.0012)$ \\
Parents married & $0.039(0.111)$ \\
Proportion of infant-toddler rooms & $0.29(0.11)^{* *}$ \\
Proportion of preschooler rooms & $-0.12(0.11)$ \\
Intercept & $6.72(0.21)^{* *}$ \\
$R^{2}(n)$ & $0.77(266)$ \\
\hline$*$ and ** indicate significantly different from zero at the $5 \%$ and $1 \%$ levels, respectively. & \\
&
\end{tabular}

and centers serving children of well-educated parents. Costs are lower for church-affiliated centers. There is no evidence that costs differ between for-profit and nonprofit centers. More importantly, in a specification (not shown here) that included an interaction between profit status and quality, the coefficient on the interaction term was small and insignificantly different from zero.

Some of the implications of these estimates are shown in table 3, which presents marginal cost and the elasticity of cost with respect to quality, overall and by state, evaluated at each firm's observed level of quality, and averaged over firms. On average, marginal cost is positive and significantly different from zero in for-profit and nonprofit centers in all states. The average elasticity of cost with respect to quality is $0.22-0.24$, which is somewhat lower than Mocan's (1997) estimate of 0.40 using the same data. The most likely reason for our lower estimate is that we estimate a long-run cost function in which all factors are assumed to be variable, whereas Mocan estimated a short-run variable cost function that treated capital inputs such as building and equipment as fixed. Figure 1 illustrates how marginal cost varies with the level of quality, based on simulations that set each firm's quality to the same level while holding all other variables fixed at their observed values, with the results averaged across firms. Marginal cost rises gradually from approximately $\$ 300$ to $\$ 400$ as quality increases.

\section{B. Price Function Estimates}

Linear regression estimates of the quality coefficients from four alternative specifications of the price function are presented in table 4 . The test statistics shown in the lower part of the table indicate that the hypothesis that the price function intercepts are identical across ZIP 
Table 3.-Estimates of Weekly Marginal Cost, Marginal Revenue, and Elasticity of Cost with Respect to Quality

\begin{tabular}{lcc}
\hline \hline & For-profit & Nonprofit \\
\hline All & & \\
Marginal cost & $332(134)$ & $319(126)$ \\
Marginal revenue & $453(121)$ & $371(103)$ \\
$\quad$ Elasticity of cost wrt quality & $0.22(0.09)$ & $0.24(0.09)$ \\
California & & \\
$\quad$ Marginal cost & $391(158)$ & $359(143)$ \\
Marginal revenue & $713(415)$ & $655(377)$ \\
Elasticity of cost wrt quality & $0.24(0.10)$ & $0.26(0.10)$ \\
Colorado & $325(133)$ & $308(122)$ \\
Marginal cost & $556(229)$ & $395(165)$ \\
Marginal revenue & $0.22(0.09)$ & $0.24(0.10)$ \\
Elasticity of cost wrt quality & & \\
Connecticut & $293(122)$ & $299(117)$ \\
Marginal cost & $319(145)$ & $269(127)$ \\
Marginal revenue & $0.24(0.10)$ & $0.23(0.09)$ \\
$\quad$ Elasticity of cost wrt quality & $338(135)$ & $309(125)$ \\
North Carolina & $244(117)$ & $169(81)$ \\
Marginal cost & $0.17(0.07)$ & $0.23(0.09)$ \\
Marginal revenue &
\end{tabular}

Standard errors (in parentheses) were computed by taking 1,000 random draws from the joint distribution of all the parameters, computing the variable of interest (for example, average marginal cost), and using the standard deviation of the resulting distribution.

codes or towns was not rejected at the $5 \%$ level for any of the states except California for the specification using town dummies. The hypothesis was not rejected at the $1 \%$ level in this case. Thus, the specification in the first row is not rejected when tested against the specifications in the second and third rows. This implies that there is relatively little variation within states in the price-quality locus. The fourth row presents results from a specification in which approximately two dozen center characteristics were included along with quality. In all states except North Carolina, the hypothesis that the coefficients on these characteristics are jointly zero was not rejected at the 5\% level of significance. Thus, we focus mainly on the results in the first row, with no location dummies and no regressors other than quality and the proportion of infants and toddlers (although we present some sensitivity analysis). The results in the first row indicate that the market rewards higher-quality care with a significantly higher price in three of the four states, with elasticities of 0.40 in California, 0.32 in Colorado, 0.22 in Connecticut, and 0.13 in North Carolina. ${ }^{18}$ Table 3 shows the average level of marginal revenue evaluated at the observed level of quality in each center, based on the results from the first row of table 4. Marginal revenue is positive and significantly different from zero in all states and for both types of firms. Figure 1 shows that marginal revenue declines sharply with quality up to about $Q=3$ and more slowly thereafter, but remains positive at all levels of quality. (This is an implication of the functional form of

\footnotetext{
${ }^{18}$ As noted previously, the quality measure we use is an average of the scores on the 32 individual ECERS items and 28 ITERS items. We reestimated the price equation including the individual item scores and found that we could not reject combining the items into a single average score for any state.
}

the price equation together with a positive coefficient on $\ln$ $Q$ in the price function.) Marginal cost and marginal revenue intersect at about $Q=4.3$ in the for-profit sector and $Q=4.1$ in the nonprofit sector.

Interpreting the price functions as market price-quality loci, they are determined by both preferences and technology and therefore do not directly reveal information about either. However, there will be a positive pricequality slope only if parents are willing to pay more for higher-quality care and if producing higher-quality care increases cost. The cost function estimates show directly that the latter condition is satisfied. The positive quality slope in the price function implies that parents are on average willing to pay more for higher-quality care, with the possible exception of North Carolina. Blau and Hagy (1998) did not find much evidence that parents are willing to pay more for regulated attributes of child care such as group size, staff-child ratio, and trained providers. However, the quality measure we use here is more closely related to child development outcomes, so it is plausible that parents would be willing to pay more for high-quality arrangements even if they are not willing to pay more for arrangements with better regulatable inputs.

\section{Objective Function Estimates}

The main finding from estimation of the firm objective function is that the coefficient on quality ( $\alpha$ in equation (6)) is zero for both for-profit and nonprofit firms. This was true in every one of the numerous specifications estimated. This implies that both types of firms behave as profit maximizers. The hypothesis that $\alpha=0$ was never rejected. ${ }^{19}$

\section{The Supply of Quality}

As noted, we simulate supply behavior by varying the intercept of the supply function $(\theta)$, and solving for each firm's optimal choice of quality for alternative values of $\theta$. We than average over firms. This can be thought of as measuring how a firm would respond to an exogenous change in the intercept of the price-quality relationship in its market. It can also be thought of as the effect of an unconditional (on quality) subsidy per hour of care provided. To provide a price metric that can be used to compute a supply elasticity, the value of $\theta$ underlying each simulation is converted to a value of $P$ by evaluating the price function at a fixed level of quality (the sample mean). ${ }^{20}$ The estimates are based on the cost function

\footnotetext{
${ }^{19}$ The estimates imply that fewer than $10 \%$ of nonprofits are constrained by either the upper or lower bound on profit. $\left(\lambda_{u}\right.$ and $\lambda_{l}$ were both estimated to be less than 0.05 on average.)

${ }^{20}$ Specifically, let $\theta_{s}$ and $\theta$, be two values of $\theta$ used in the simulations. For each for-profit firm, we solve the equation $M C(Q)-$ $M R(Q)=0$ numerically for $Q_{s}$, the optimal value of $Q$ given $\theta_{s}$, where $M R=\omega R / Q, R=\exp \left\{\theta_{s}+\omega \ln Q+\eta I_{j}\right\} H_{j}, M C=\beta_{1} C$, and $C=$ $\exp \left\{\beta_{0}+\beta_{1} Q+\beta_{2} H_{j}+\beta_{3} g_{j}+\beta_{4} H_{j}^{2}+\beta_{5} g_{j}^{2}+\beta_{6} H_{j} g_{j}+\beta_{7} R_{j}+\right.$ $\left.\beta_{8} M_{j}+\sum \beta_{8+i} W_{j i}\right\}$. We do the same for $Q_{t}$, the optimal value of $Q$
} 
Figure 1A.-Estimated Average Marginal Cost and Marginal Revenue, For-Profit Centers

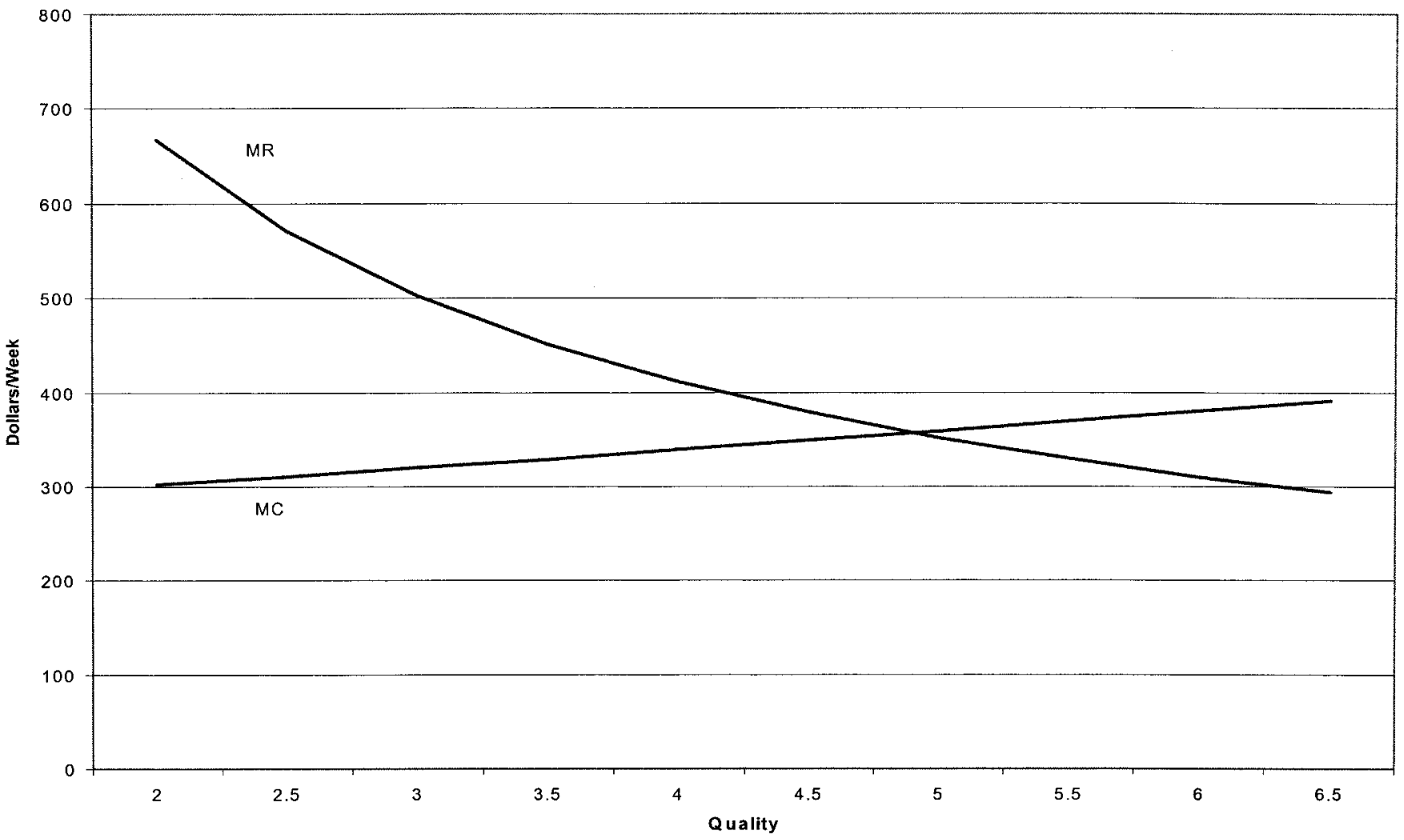

Figure 1B.-Estimated Average Marginal Cost and Marginal Revenue, Nonprofit Centers

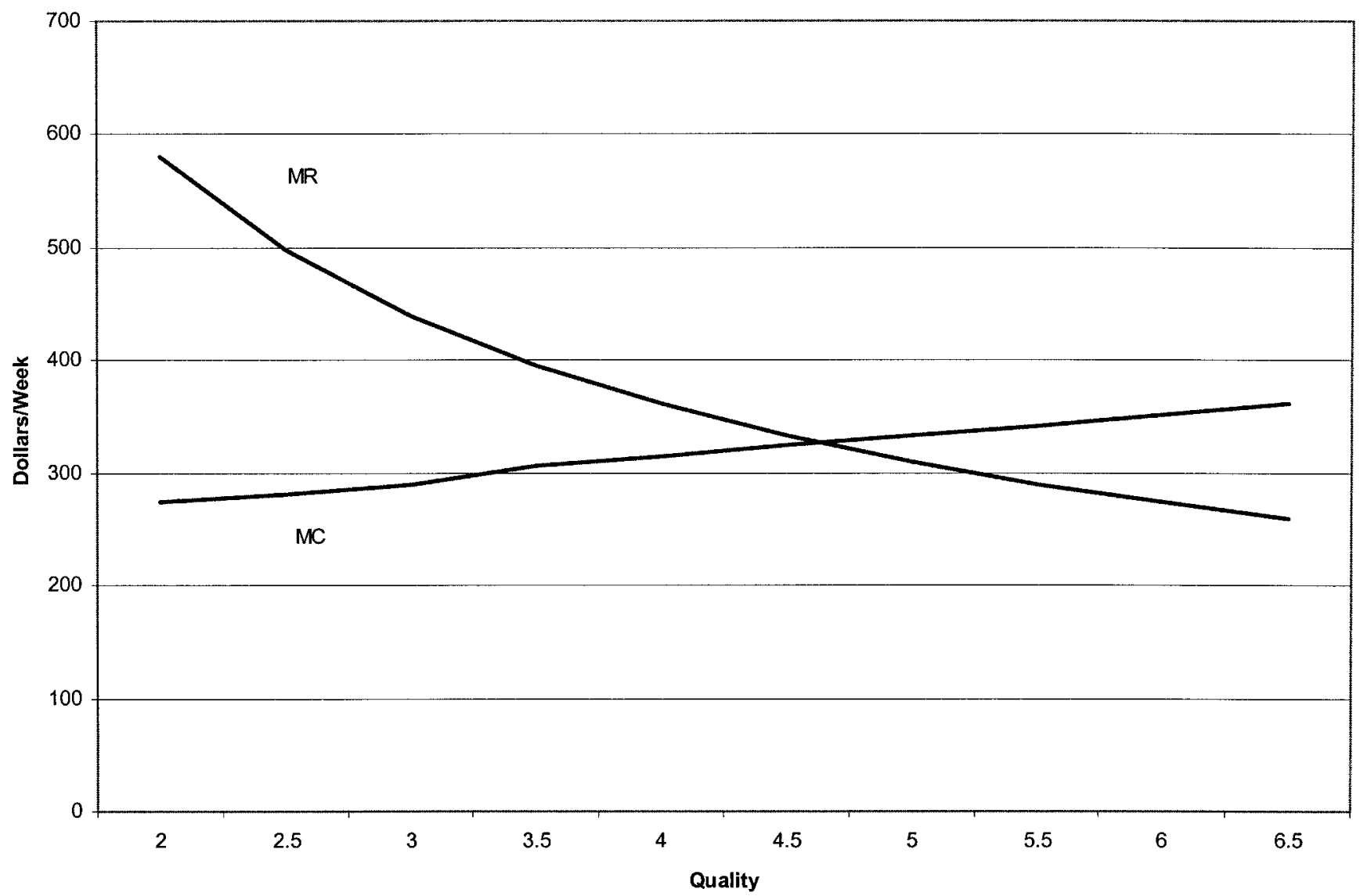


Table 4.-Elasticity of Price with ResPect to Quality from Fee Regressions

\begin{tabular}{llccc}
\hline \hline & California & Colorado & Connecticut & North Carolina \\
\hline & & \multicolumn{2}{c}{ Coefficient on Ln Quality } \\
No geographic controls & $0.40(0.16)^{* *}$ & $0.32(0.11)^{* * *}$ & $0.22(0.10)^{* *}$ & $0.13(0.08)$ \\
ZIP codes & $0.03(0.24)$ & $0.16(0.19)$ & $0.26(0.13)^{* *}$ & $0.09(0.11)$ \\
Towns & $0.16(0.19)$ & $0.25(0.11)^{* *}$ & $0.19(0.12)^{*}$ & $0.16(0.09)$ \\
No geographic controls; includes other regressors & $0.51(0.18)^{* * *}$ & $0.08(0.14)$ & $0.17(0.10)^{*}$ & $0.18(0.09)^{* *}$
\end{tabular}

Test Statistics

\begin{tabular}{|c|c|c|c|c|}
\hline ZIP code effects are zero & $1.73 \sim F(71,25)$ & $0.82 \sim F(56,43)$ & $1.49 \sim F(54,44)$ & $0.97 \sim F(45,44)$ \\
\hline Town effects are zero & $1.79 \sim F(53,43) * *$ & $1.45 \sim F(9,90)$ & $1.06 \sim F(33,65)$ & $1.00 \sim F(26,73)$ \\
\hline Other regressor effects are zero & $1.42 \sim F(18,76)$ & $1.36 \sim F(20,74)$ & $1.63 \sim F(17,81)$ & $3.30 \sim F(21,73) * * *$ \\
\hline
\end{tabular}

results in table 2 and the price function results in the first row of table 4 , without location dummies. ${ }^{21}$

The simulated quality supply function for all states combined is shown in figure 2 separately for for-profits and nonprofits. The supply functions are upward sloping, and the average arc price elasticity of supply, shown in table 5 by state and overall, is positive in every case. The average price elasticity is 0.66 among for-profits and 0.48 among nonprofits. These figures indicate that an increase in the intercept of the price function that causes a $10 \%$ increase in price for a given quality would cause firms to raise quality by $6.6 \%$ and $4.8 \%$, respectively. The more-elastic supply of quality in the for-profit sector is consistent with the notion that many nonprofits face constraints on improving quality due to reliance on donations. In economic terms, these moderately large elasticities result from the fact that cost is estimated to increase only modestly with increases in quality, whereas the market price can be increased fairly substantially as quality increases. From a policy perspective, the simulation results can be interpreted as the effects that would result from increased demand for child care generated by child care subsidies to consumers. Thus, consumer subsidies such as the Dependent Care Tax Credit and the

given $\theta_{t}$. We then compute the arc elasticity $\left[\left(Q_{s}-Q_{t}\right) /\left(Q_{s}+\right.\right.$ $\left.\left.Q_{t}\right)\right] /\left[\left(P_{s}-P_{t}\right) /\left(P_{s}+P_{t}\right)\right]$, where $P_{s} \equiv \exp \left\{\theta_{s}+\omega \ln \bar{Q}+\eta I_{j}\right\}, P_{t} \equiv$ $\exp \left\{\theta_{t}+\omega \ln Q+\eta I_{j}\right\}$, and $\ln \bar{Q}$ is the sample mean value of $\ln Q$ (not the simulated value). Finally, we average over firms. For nonprofits, we follow the same approach except that we also compute $Q_{s l}$ and $Q_{s u}$ as the solutions to $\pi(Q)=\mu_{l}$ and $\pi(Q)=\mu_{u}$, respectively. These are the optimal $Q$ 's given that the lower and upper bound constraints on profit are binding, whereas $Q_{s}$ is the optimal $Q$ given that neither constraint is binding. The simulated optimal quality is then computed as the weighted average $\lambda_{l} Q_{s l}+\lambda_{u} Q_{s u}+\left(1-\lambda_{l}-\lambda_{u}\right) Q_{s}$, where the $\lambda$ 's (defined in equations (7) and (8)) are the probabilities of being at the profit bounds. Note that the estimated value of $\alpha=0$ is used for both for-profits and nonprofits. The estimates of $\mu_{l}$ and $\mu_{u}$ are $-\$ 233 /$ week and $-\$ 21 /$ week, respectively.

${ }^{21}$ As noted, we assume that the quantity of services $(H)$ and characteristics of the families served $(M)$ are determined by consumers in response to the price and quality offered by the firm. However, we do not allow $H$ and $M$ to respond to changes in $\theta$ in the simulations. The simulations should be interpreted with this point in mind.
Child Care and Development Fund that are not targeted specifically toward high-quality child care are nevertheless likely to increase the supply of higher-quality child care. The quality supply elasticity appears to be larger in the lower-quality states (Colorado and North Carolina).

Because the major cost of child care is labor, another policy of interest is a wage subsidy for child care labor. Figure 3 shows the results of quality supply simulations in which wage rates of the three types of child care labor are set at alternative values. Quality supply appears to be fairly sensitive to the wage rate, with average elasticities, shown in table 5 , of -0.77 to -0.80 . Thus, wage subsidies could be another method of inducing an increase in the supply of quality in child care. ${ }^{22}$

\section{E. Sensitivity Analysis}

Table 6 reports price and wage elasticities of quality supply from a variety of different specifications, averaged over all four states. Row 1 of each panel reproduces the results from table 5, based on OLS estimates of the cost function in table 2 and the price function estimates in the first row of table 4. We refer to this as the baseline specification. Row 2 reports results based on IV estimation of the cost function, treating quality, output, group size, and wages as endogenous, and using ZIP code dummies as identifying instruments. The IV estimate of the coefficient on quality in the cost function was 0.053 (0.025) compared to the OLS estimate of $0.056(0.023)$. Hence, there is little evidence that quality is endogenous in the cost function. The for-profit supply elasticities in row 2 based on the IV estimates are very similar to the baseline estimates, whereas the nonprofit elasticities are much smaller in absolute value. Given the absence of evidence of endogeneity bias, we put more weight on the first-row estimates.

\footnotetext{
${ }^{22}$ These simulations use the same method described in footnote 19 , using the wage rates $W_{i}$ as the forcing variables instead of $\theta$
} 
Figure 2.-Quality Supplied at Alternative Prices

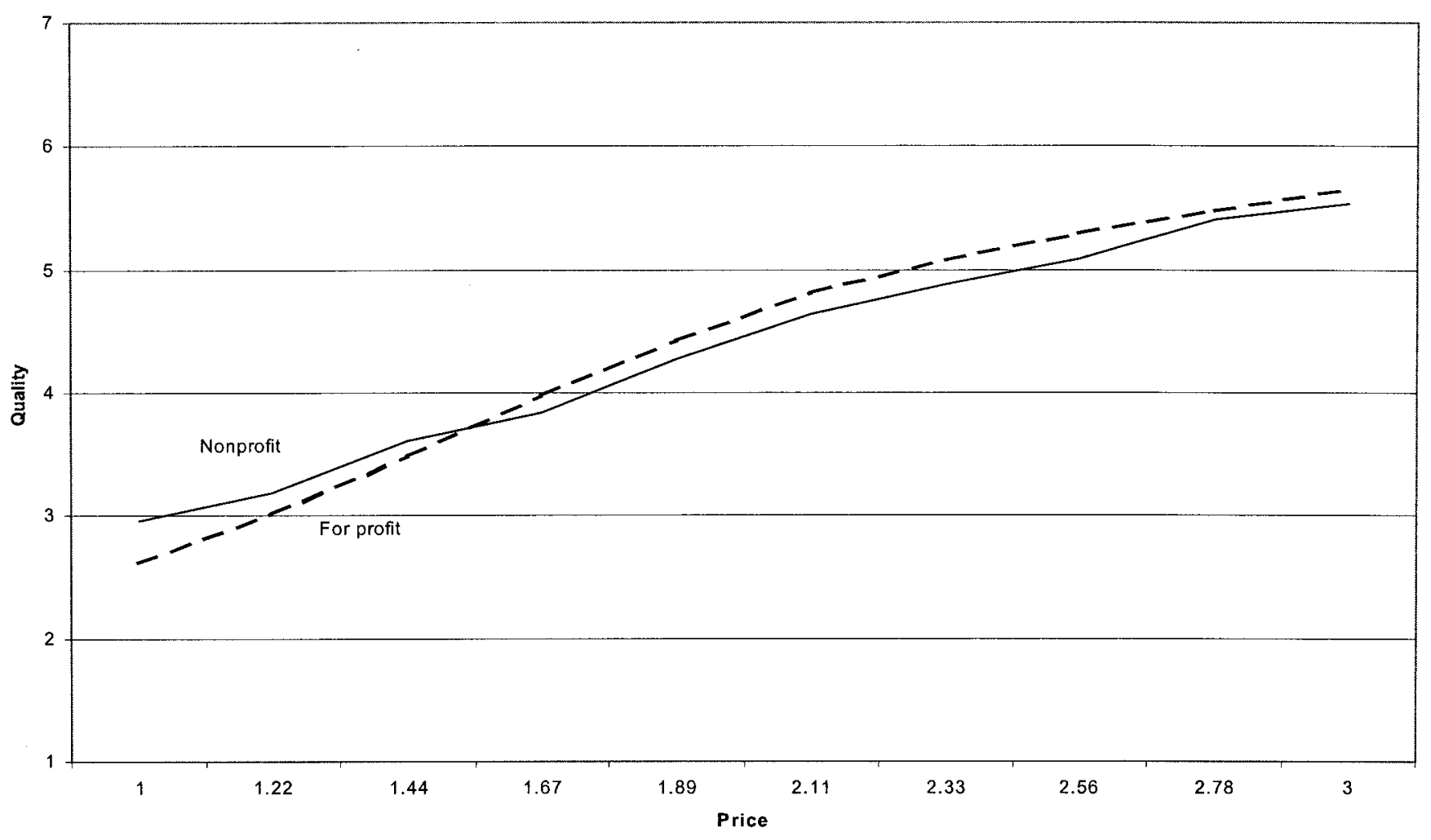

Row 3 reports results from selectivity-corrected cost function estimates. Recall that the sample on which the cost function is estimated includes only centers that use all three types of labor. To determine whether this causes selection bias, we used the full sample of centers to estimate a probit model of the decision to use all three types of labor, with ZIP code dummies as identifying variables in the first stage. A selectivity correction term computed from the first-stage probit estimates was then included in the cost function model estimated on the selected sample, following Heckman (1979). The quality coefficient in this specification was 0.056 (0.021), identical to the OLS estimate, and the elas-

Table 5.-Elasticity of Quality Supply with Respect to PRice AND Wage Rate

\begin{tabular}{lrrrrr}
\hline \hline & All States & CA & CO & CT & \multicolumn{1}{c}{ NC } \\
\hline & \multicolumn{7}{c}{ For-profit } \\
Price elasticity & 0.66 & 0.63 & 0.58 & 0.69 & 0.89 \\
Wage elasticity & -0.80 & -0.73 & -0.86 & -0.65 & -1.00 \\
& \multicolumn{7}{c}{ Nonprofit } \\
& \multicolumn{7}{c}{0.45} & & \\
Price elasticity & 0.48 & 0.45 & 0.76 & 0.35 & 0.84 \\
Wage elasticity & -0.77 & -0.56 & -0.96 & -0.58 & -1.04 \\
\hline
\end{tabular}

The ECERS/ITERS quality scale has a minimum value of 1 and a maximum of 7 . These bounds were imposed when solving for the optical level of quality. The wage simulations vary the wages of all three teacher types jointly. The wage rates shown in figure 3 are for the lowest-education group (high school graduate or less). The wages of college attendees in the simulations are $\$ 2$ more than for the lowest group, and the wage rate for college graduates is $\$ 4$ more. The simulations are based on the parameter estimates in tables 2 and 4 . The elasticities are the average arc elasticities from one simulated value to the next, averaged over the simulations. The simulated values are shown in figures 2 and 3 for all states combined. ticities in row 3 are thus very similar to the baseline estimates.

Row 4 reports elasticities based on price functions with town dummies in the fee equation (from row 3 of table 4), and row 5 reports results based on including ZIP code dummies in the fee equation (from row 2 of table 4). These cause some fairly large changes in the elasticities in some cases. However, the hypothesis that town and ZIP code dummies could be excluded from the fee equations was never rejected at the $1 \%$ level of significance. Hence, the sensitivity of the results to this specification change is not of great importance.

Row 6 reports results based on adding interactions between states dummies and quality in the cost function. The hypothesis that the coefficient estimates on these interactions were jointly zero was not rejected. Row 7 reports results based on adding an interaction between quality and the dummy for receiving more than half of center revenue from public subsidies (pubsub) in the cost function. This was the only case in which a quality interaction effect was significantly different from zero. The coefficient estimate on quality in this specification was $0.075(0.023)$ and the quality-pubsub interaction coefficient was $-0.26(0.07)$. This does not affect the elasticities for the for-profits much, but results in much smaller elasticities in absolute value for the nonprofits. Row 8 reports results in which the full sample of centers was used in the cost function estimation, with wages imputed for centers that did not use a given type 
Figure 3.-Quality Supplied at Alternative Teacher Wage Rates

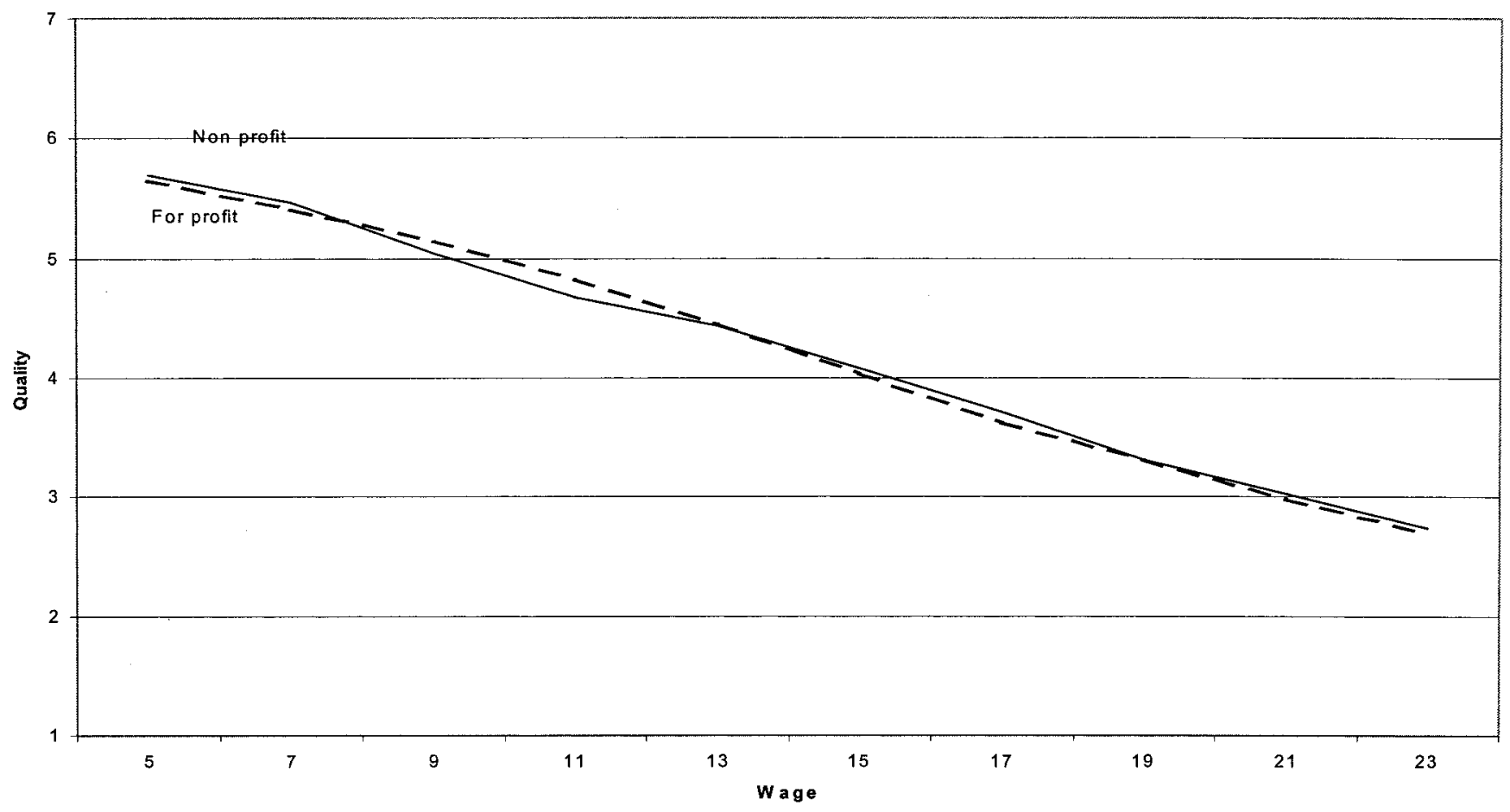

of labor, based on the state average for that type of labor by for-profit/nonprofit status. The quality coefficient in this version of the cost function was $0.068(0.020)$ compared to $0.056(0.023)$ in the baseline model. This has little impact on the average elasticities, although some of the statespecific elasticities not shown in the table did change substantially. Finally, row 9 treats nonprofits as if they faced no upper or lower bounds on profit. This hardly affects the results.

\section{Conclusions}

One of the goals of federal and many state child care policies is to improve the quality of child care. This paper analyzes the behavior of suppliers of child care and reports results that are somewhat encouraging from a policy perspective. The cost of improving quality is estimated to be fairly modest, and parents are on average willing to pay between $0.13 \%$ and $0.40 \%$ more for child care with $1 \%$ higher quality, depending on the state. The resulting price elasticity of quality supply is 0.66 among for-profit suppliers and 0.48 among nonprofits, averaged across states. The average wage elasticity of quality supply is about -0.8 . Thus, policies that would be relatively straightforward to implement-such as across-the-board child care price and wage subsidies - would have moderately large effects on the average level of child care quality supplied according to the results presented here. Such policies are straightforward because they do not impose heavy information requirements for implementation. Alternative policies that might have larger effects on quality would have to be targeted at centers that are willing to maintain a given level of quality or achieve a specified amount of quality improvement, but

\begin{tabular}{|c|c|c|}
\hline \multicolumn{3}{|l|}{ Price Elasticities } \\
\hline Specification & For-profit & Nonprofit \\
\hline 1. Baseline & 0.66 & 0.48 \\
\hline 2. Cost function estimated by IV & 0.62 & 0.03 \\
\hline 3. Cost function selectivity-corr. & 0.65 & 0.51 \\
\hline 4. Town dummies in fee equation & 0.73 & 0.81 \\
\hline 5. ZIP code dummies in fee equation & 0.34 & 0.27 \\
\hline 6. State dummies $*$ quality in cost function & 0.42 & -0.21 \\
\hline 7. Pubsub $*$ quality in cost function & 0.66 & -0.08 \\
\hline 8. Full sample, imputed wages & 0.66 & 0.33 \\
\hline 9. No extra constraints for nonprofits & 0.69 & 0.57 \\
\hline \multicolumn{3}{|l|}{ Wage Elasticities } \\
\hline 1. Baseline & -0.80 & -0.77 \\
\hline 2. Cost function estimated by IV & -0.75 & -0.39 \\
\hline 3. Cost function selectivity-corr. & -0.80 & -0.77 \\
\hline 4. Town dummies in fee equation & -0.78 & -0.87 \\
\hline 5. ZIP code dummies in fee equation & -0.33 & -0.27 \\
\hline 6. State dummies $*$ quality in cost function & -0.25 & 0.16 \\
\hline 7. Pubsub $*$ quality in cost function & -0.60 & 0.08 \\
\hline 8. Full sample, imputed wages & -0.70 & -0.56 \\
\hline 9. No extra constraints for nonprofits & -0.78 & -0.77 \\
\hline
\end{tabular}

The baseline specification uses results from the cost function estimates in table 2 and the fee equation estimates in table 4 . The cost function in the baseline specification is estimated by OLS, and the fee equation in the baseline specification does not contain any location dummies. The results in rows 2-9 use the baseline specification except for the difference noted in the first column. 
measuring quality is costly for government monitoring agencies.

The estimates presented here have some limitations that should be kept in mind. Only about $30 \%$ of preschool-age children who are cared for by someone other than a parent receive care in a center. It is important to learn more about the supply of quality in other child care settings; the sample of centers available for analysis is relatively small and is not necessarily nationally representative. Thus, it would be useful to replicate our results with other data and larger samples. Finally, the interpretation of our results relies on the assumption that firms seek to minimize cost. We could not test this assumption because we lack data on the prices of nonlabor inputs. Testing this assumption should be a priority for future research on the supply of child care. Despite these caveats, the results presented here appear to be generally quite robust and potentially useful as a basis for policy analysis.

\section{REFERENCES}

Bergmann, Barbara R., Saving our Children from Poverty: What the United States Can Learn from France (New York: Russell Sage Foundation, 1996).

Blau, David M., "The Production of Quality in Child Care Centers," Journal of Human Resources 32:2 (1997), 354-387.

, "The Effect of Child Care Characteristics on Child Development," Journal of Human Resources 34:4 (1999), 786-822.

, "The Production of Quality in Child Care Centers: Another Look," Applied Developmental Science 4:3 (2000), 136-148. , The Child Care Problem: An Economic Analysis (New York: Russell Sage Foundation, 2001).

Blau, David M., and Alison P. Hagy, "The Demand for Quality in Child Care," Journal of Political Economy 106:1 (1998), 104-146.

Blau, David M., and H. Naci Mocan, "The Effects of Regulations on the Child Care Market," University of Colorado-Denver working paper (September 2000).

Blau, David M., and Phillip Robins, "Child Care Costs and Family Labor Supply," this REVIEW 70:3 (1988), 374-381.

Caspar, Lynne, "Who's Minding Our Preschoolers? Fall 1994," Current Population Reports, Household Economic Studies, P70-62, U.S. Bureau of the Census (1997).

Connelly, Rachel, "The Effect of Child Care Costs on Married Women's Labor Force Participation," this REVIEW 74:1 (1992), 83-90.

Council of Economic Advisors, "The Economics of Child Care," mimeograph (Washington, DC, 1997).

Gertler, Paul J., and Donald M. Waldman, "Quality-Adjusted Cost Functions and Policy Evaluation in the Nursing Home Industry," Journal of Political Economy 100:6 (1992), 1232-1256.

Hagy, Alison P., "The Demand for Child Care Quality," Journal of Human Resources 33:3 (1998), 683-710.

Hanushek, Eric A., et al., Making Schools Work: Improving Performance and Controlling Costs (Washington DC: Brookings Institution, 1994).

Hansmann, Henry, "The Changing Roles of Public, Private, and Nonprofit Enterprise in Education, Health Care, and Other Human Services" (pp. 245-271), in Victor Fuchs (Ed.), Individual and Social Responsibility: Child Care, Education, Medical Care, and Long-Term Care in America (Chicago: University of Chicago Press, 1996).

Harms, Thelma, Deborah Cryer, and Richard Clifford, Infant/Toddler Environment Rating Scale (New York: Teachers College Press, 1990).
Harms, Thelma, and Richard Clifford, Early Childhood Environment Rating Scale (New York: Teachers College Press, 1980).

Hayes, Cheryl D., John L. Palmer, and Martha L. Zaslow (Eds.), Who Cares for America's Children? Child Care Policy for the 1990s (Washington, DC: National Academy Press, 1990).

Heckman, James J., "Sample Selection Bias as a Specification Error," Econometrica 47:1 (1979), 153-162.

Helburn, Suzanne W. (Ed.), Cost, Quality and Child Outcomes in Child Care Centers, Technical Report (Denver: Center for Research on Economic and Social Policy, University of Colorado at Denver, 1995).

Kisker, Ellen Eliason, Sandra L. Hofferth, Deborah A. Phillips, and Elizabeth Farquhar, "A Profile of Child Care Settings: Early Care and Education in 1990" (Princeton: Mathematica Policy Research, 1991).

Lakdawalla, Darius, and Tomas Philipson, "Nonprofit Production and Competition," National Bureau of Economic Research working paper no 6377 (1998).

Leibowitz, Arleen, Linda J. Waite, and Christina Witsberger, "Child Care for Preschoolers: Differences by Child's Age," Demography 25:2 (1988), 205-220.

Love, John M., Peter Z. Schochet, and Alicia L. Meckstroth, "Are They in Any Real Danger? What Research Does-And Doesn't-Tell Us About Child Care Quality and Children's Well-Being," Mathematica Policy Research working paper (1996).

Michalopoulos, Charles, Philip K. Robins, and Irwin Garfinkel, "A Structural Model of Labor Supply and Child Care Demand," Journal of Human Resources 27:1 (1992), 166-203.

Mocan, H. Naci, "Quality Adjusted Cost Functions for Child Care Centers," American Economic Review Papers and Proceedings 85:2 (1995), 409-413.

, "Cost Function, Efficiency, and Quality in Day Care Centers," Journal of Human Resources 32:4 (1997), 861-891.

Mocan, H. Naci, and Erdal Tekin, "Nonprofit Sector and Part-time Work: An Analysis of Employer-Employee Matched Data of Child Care Workers," NBER working paper no. 7977 (2000).

Mukerjee, Swati, and Ann Dryden Witte, "Provision of Child Care: Cost Functions for Profit-Making and Non-profit Day Care Centers," Journal of Productivity Analysis 4:1-2 (1993), 145-163.

Powell, Irene, and James Cosgrove, "Quality and Cost in Early Childhood Education," Journal of Human Resources 27:3 (1992), 472-484.

Preston, Anne, "Efficiency, Quality, and Social Externalities in the Provision of Day Care: Comparisons of Nonprofit and For-Profit Firms," Journal of Productivity Analysis 4:1-2 (1993), 165-182.

Ribar, David C., "A Structural Model of Child Care and the Labor Supply of Married Women," Journal of Labor Economics 13:3 (1995), 558-597.

Robins, Phillip K., "Child Care Policy and Research: An Economist's Perspective" (pp. 11-41), in David Blau (Ed.), The Economics of Child Care (New York: The Russell Sage Foundation, 1991).

Rose-Ackerman, Susan, "Altruism, Nonprofits, and Economic Theory," Journal of Economic Literature 34:2 (1996), 701-728.

Rosen, Sherwin, "Hedonic Prices and Implicit Markets: Product Differentiation in Pure Competition," Journal of Political Economy 82:1 (1974), 34-55.

Walker, James, "Public Policy and the Supply of Child Care Services" (pp. 51-77), in David Blau (Ed.), The Economics of Child Care (New York: Russell Sage Foundation, 1991).

, "New Evidence on the Supply of Child Care," Journal of Human Resources 27:1 (1992), 40-69.

Weisbrod, Burton A., "The Nonprofit Mission and Its Financing," Journal of Policy Analysis and Management 17:2 (1998), 165-174.

Whitebook, Marcy, Carollee Howes, and Deborah Phillips, Who Cares? Child Care Teachers and the Quality of Care in America, final report of the National Care Staffing Study (Oakland: Child Care Employee Project, 1990). 


\section{APPENDIX}

The ECERS items are listed here. The ECERS items that are also part of the ITERS scale are indicated with an $(*)$. Additional ITERS items are listed following the ECERS items.

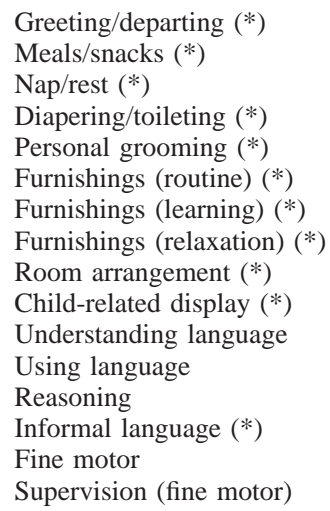

Gross motor space

Gross motor equipment

Gross motor time

Supervision (gross motor)

Art (*)

Music/movement (*)

Blocks (*)

Sand/water $(*)$

Dramatic play (*)

Schedule (creative)

Supervision (creative)

Space to be alone

Free play

Group time

Cultural awareness (*)

Tone

Active physical play

Peer interaction

Adult-child interaction

Discipline

Schedule of daily activities

Examples of instructions to raters include the following:

Item
$\begin{aligned} & \text { Understanding } \\ & \text { language }\end{aligned}$

Art activities

$$
\text { Inadequate }
$$

$$
1
$$

Few materials present and little use of materials to help children understand language (e.g., no scheduled daily story time).

Few art materials available; regimented use of materials (e.g., mostly teacher-directed).
2
Some materials present, but not regularly available or used for language development.

Some materials available for free choice but major emphasis on projects that are like an example shown.
4

Many materials available for free choice and supervised use. At least one planned activity daily.

Individual expression and free choice encouraged with art materials. Few projects that are like an example shown.
6
Everything in 5 plus teacher provides good language model throughout the day (e.g., gives clear directions, uses words exactly in descriptions).

Variety of materials available for free choice. Attempt to relate art activities to other experiences. 